\title{
MENINGKATAN KINERJA SUMBER DAYA MANUSIA (SDM) MELALUI MOTIVASI, LINGKUNGAN KERJA, DISIPLIN, DAN KOMITMEN
}

\author{
Nailur Rohmah \\ Program Studi Pendidikan Guru Sekolah Dasar \\ Fakultas Keguruan dan Ilmu Pendidikan \\ Universitas Nahdlatul Ulama Sidoarjo \\ Email: nay.rohmah25@gmail.com
}

\section{Pengantar}

Di era modern ini, ditandai dengan perubahan-perubahan yang begitu cepat dan sigifikan, suatu organisasi atau lembaga institusi diharapkan untuk mengadakan sebuah penyesuaian dalam semua aspek yang ada di organisasi tersebut. Dengan keterbatasan sumber daya manusia yang ada, organisasi diharapkan dapat mengoptimalkannya sebaik mungkin sehingga tercapailah tujuan organisasinya. Dalam era saat ini, dimana teknologi serta peradaban sangat maju dan berkembang, menuntut Sumber Daya Manusia untuk berkontribusi dan memiliki semangat serta kedisiplinan yang lebih tinggi dalam melakukan peran dan fungsinya baik secara individual maupun dalam berorganisasi. Maka dari itu, maju tidaknya negara bergantung dari kemampuan sumber daya manusia yang ada didalamnya. Sumber daya manusia mempunyai fungsi penting, dalam interaksinya dengan faktor mesin, material, metode. Kompleksitas tersebut dapat menentukan kualitas manusia. Oleh karena itu, kita diharuskan untuk selalu berhati-hati serta memperhatikan setiap aspeknya.

\section{Motivasi}

Motivasi merupakan dorongan yang muncul dari dalam diri seseorang secara sadar ataupun tak sadar untuk melakukan perbuatan dengan tujuan tertentu (KBBI, 2018). Melalui motivasi ini kita bisa meningkatkan kinerja SDM dalam mengikuti suatu hal seperti organisasi. Motivasi kerja dapat berangsur-angsur hilang di tengah beban pekerjaan yang meningkat. Semangat kerja karyawan yang menurun akan berdampak pada kinerjanya yang semakin memburuk, produktivitas juga semakin rendah, dan 
akhirnya akan menghambat tujuan perusahaan tersebut untuk tercapai. Maka dari itu, dibutuhkan peranan seorang pemimpin yang mampu memompa semangat mereka kembali.

\section{Disiplin}

Disiplin adalah pola perilaku yang menghasilkan sebuah karakter tertentu. Terlebih menghasilkan peningkatan mental dan moral yang lebih teratur. Disiplin merupakan kontrol yang diperoleh dengan menegakkan kepatuhan terhadap perintah (Hougton). Disiplin ditujukan kepada siapapun: (1) keluarga, memiliki peranan penting dalam membentuk kedisiplinan. (2) teman, pergaulan yang baik akan menghasilkan kebaikan begitu juga sebaliknya sebab sifat kita tidak akan jauh dari mereka. (3) lingkungan, lingkungan juga sangat berpengaruh dengan disiplin karena jika kita mengikuti lingkungan yang sifatnya melanggar disiplin, maka kita akan mengikuti mereka dengan sendirinya. Penelitian yang dilakukan oleh Lory (2008) mengatakan bahwa disiplin termasuk keinginan dari kedua pihak agar terus berkomitmen. Ciptakan kedisiplinan mulailah dari sekarang juga, kapanpun, dan dimanapun itu.

\section{Lingkungan Kerja}

Lingkungan kerja adalah salah satu faktor yang bisa mempengaruhi produktivitas dan efektivitas kerja pegawai. Dapat berupa lingkungan material seperti sarana dan tempat produksi, "lingkungan kerja dibentuk oleh adanya komitmen eksternal dan komitmen internal yang sangat ditentukan oleh kemampuan pemimpin serta lingkungan organisasi membutuhkan tindakan dan sikap professional dalam menngerjakan tanggung jawab dan tugas perusahaan”. Indriyani (2011) berpendapat bahwa terdapat adanya pengaruh yang sangat kuat antara lingkungan bekerja dengan kinerja para karyawan pada Perlindungan Masyarakat kota Bandung dan Pemberdayaannya, juga Badan Kesatuan Bangsa. Khoiriyah (2009) berpendapat bahwa lingkungan kerja juga bisa berpengaruh positif terhadap kinerja para karyawan. Penelitian Sihombing (2011) mengemukakan bahwa motivasi dan lingkungan kerja secara bersama-sama berpengaruh tinggi yang signifikan terhadap komitmen kerja pegawai PT BRI, Tbk cabang.

\section{Komitmen}


Hasil studi Christina dan Maren (2010) mengemukakan bahwa kinerja SDM juga dipengaruhi oleh komitmen. Komitmen berorganisasi merupakan kekuatan relatif dari karyawan untuk mengidentifikasi keterlibatan dirinya terhadap bagian organisasi. Keberhasilan tujuan organisasi sangatlah ditentukan dengan keberhasilan dalam mengelola SDM itu sendiri. Dalam studi MSDM, komitmen organisasional sebagai salah satu aspek yang bisa mempengaruhi perilaku manusia dalam berorganisasi dan menjadi hal penting yang banyak didiskusikan dan diteliti. Kinerja karyawan juga dipengaruhi komitmen organisasional. Karyawan mempunyai keterlibatan yang tinggi dalam bekerja serta tidak ada keinginan untuk keluar perusahaan tersebut. Dalam hal ini merupakan modal untuk mendorong produktivitas yang tinggi.

\section{Kinerja SDM}

Kinerja karyawan merupakan hasil pekerjaan karyawan selama masa bekerja yang telah ditentukan dibedakan dengan berbagai aspek, misal standar, target atau penilaian yang sudah disepakati sebelumnya. Indikatornya adalah :1.kualitas kerja karyawan, 2.kuantitas pekerjaan karyawan, dan 3.kontribusi pada organisasi. Kinerja mengukur seberapa baik karyawan dalam memenuhi persyaratan untuk sebuah pekerjaan. Pengertian kinerja adalah catatan hasil yang dicapai dalam melaksanakan fungsi khusus pekerjaan atau kegiatan bekerja selama periode tertentu yang telah ditunjukkan melalui proses atau metode bekerja dan hasil yang telah dicapai.

\section{Model Empirik Penelitian}




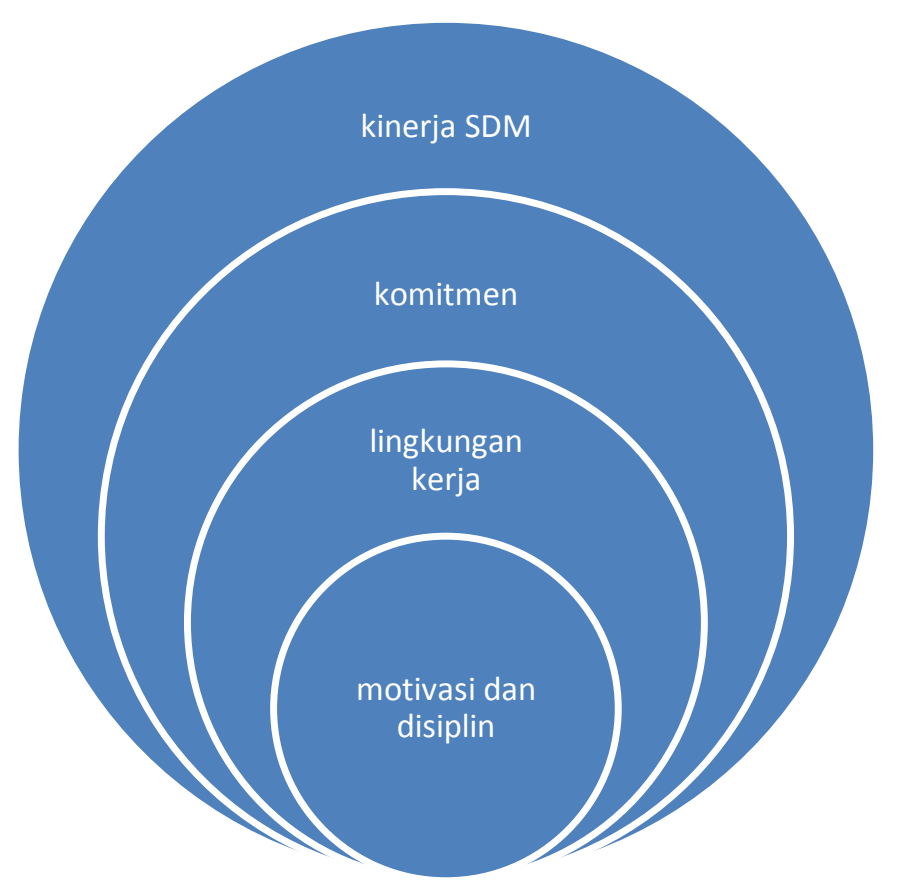

\section{Penutup}

1. Adanya pengaruh motivasi terhadap komitmen, semakin baik motivasi yang menguatkan dirinya maka akan meningkatkan komitmennya.

2. Disiplin, semakin disiplin semakin meningkatkan komitmen juga.

3. Pengaruh motivasi kinerja SDM makin baik motivasi dalam dirinya akan meningkatkan kinerjanya.

4. Pengaruh lingkungan pekerjaan terhadap kinerja SDM, jika lingkungan kerja kondusif maka akan meningkatkan kinerjanya.

5. Adanya pengaruh komitmen, makin tinggi komitmen akan meningkatkan kinerja SDM.

\section{Daftar Pustaka}

AgungPrihantoro. (2015). Pengaruh Motivasi Kerja, Disiplin Kerja, Lingkungan Kerja dan Komitmen Terhadap Kinerja Kauawan. Jurnal EMBA.

Wahyuningrum, 2008.Hubungan Kepuasan ,Kemampuan dan Disiplin Bekerja Dengan Kinerja Para Pegawai. Program Pascasarjana., UNDIP Semarang.

Feni Widaningsih, 2010. Pengaruh Disiplin, Motivasi Dan Kepuasan Kerja Dengan Kinerja Pegawai. Program Sarjana.FakultasEkonomi UMS Surakarta. 
Anisa Novitasari, 2008. Hubungan Motivasi Dan Disiplin Kinerja Pegawai. Program Sarjana. FISIP UNDIP Semarang.

https://www.slideshare.net/magdalenaPSN/artikel-ilmiah-msdm

https://media.neliti.com/media/publications/22850-ID-peningkatan-kinerja-sumberdaya-manusia.pdf 